УДК 504.064.2:528 ОЦЕНКА ЭРОЗИОННОЙ РАСЧЛЕНЕННОСТИ ВОДООХРАННОЙ
ЗОНЫ ТАГАНРОГСКОГО ЗАЛИВА С ПРИМЕНЕНИЕМ ДАННЫХ
ДИСТАНЦИОННОГО ЗОНДИРОВАНИЯ И ГИС-ТЕХНОЛОГИЙ ДИСТАНЦИОННОГО ЗОНДИРОВАНИЯ И ГИС-ТЕХНО,
Подколзина Д.А., Беспалова Е.В., Скляренко Г.Ю.

\author{
Южный федеральный университет, Ростов-на-Дону, е-mail: Podkolzina@sfedu.ru
}

\begin{abstract}
Характер и интенсивность эрозионных процессов, происходящих в водоохранной зоне (ВО3) водного объекта, являются важными параметрами, в значительной степени определяющими возможности ее хозяйственного освоения. Овражно-балочная эрозия влияет на стабильность положения береговой линии, интенсивность и объемы выноса в водный объект материала разрушения берегов, т.е. на характеристики, имеющие существенное, а нередко и решающее значение для принятия управленческих решений по осуществлению хозяйственных и природоохранных мероприятий в водоохранной зоне. На основе камеральных исследований была отработана методика и выполнена оценка интенсивности проявления эрозионных процессов, происходящих в водоохранной зоне Таганрогского залива. Использовались такие методы, как: картографический метод, ГИС-технологии, метод классификаций, визуальное дешифрирование, которые позволяют очень точно оконтурить на местности эрозионные объекты и определять их морфометрические характеристики. Оценка развития эрозионных процессов на территории водоохранной зоны Таганрогского залива проводилась с использованием мирового снимка из платформы ArcGis за 2019 г. с пространственным разрешением до 1 м. Применение инструментария программы ArcGIS позволило без проведения трудоемких инструментальных полевых исследований определить наиболее пораженные эрозионными процессами участки ВОЗ Таганрогского залива. На основе полученных морфометрических характеристик рассчитаны коэффициенты, позволяющие определять степень расчлененности территории: коэффициент расчлененности, среднее расстояние между соседними тальвегами эрозионной сети, коэффициент заовраженности. Установлено, что в пределах ВО3 Таганрогского залива показатель эрозионной расчлененности варьируется от 0 до 3,07 км/ км2 при среднем значении 1,53 км/км2, сгущение тальвегов изменяется от 0,09 икм до 0,72 км, показатель заовраженности достигает на разных участках от $0 \%$ до $8,12 \%$.
\end{abstract}

Ключевые слова: водоохранная зона, овражная-балочная сеть, горизонтальное эрозионное расчленение, морфометрические характеристики оврага, геоинформационные системы, тальвег, Таганрогский залив

\title{
ASSESSMENT OF THE EROSION SEPARATION OF THE TAGANROG BAY WATER PROTECTION ZONE USING REMOTE SENSING DATA AND GIS TECHNOLOGIES
}

\author{
Podkolzina D.A., Bespalova E.V., Sklyarenko G.Yu. \\ Southern Federal University, Rostov-on-Don, e-mail: Podkolzina@sfedu.ru
}

\begin{abstract}
The nature and intensity of erosion processes occurring in the water protection zone (WPZ) of a water body are an important parameter that largely determines the possibilities of its economic development. Gully-beam erosion affects characteristics that are essential, and often crucial for making managerial decisions on the implementation of economic and environmental measures. On the basis of desk studies, a methodology was developed and an assessment of the intensity of the manifestation of erosion processes occurring in the water protection zone of the Taganrog Bay was performed. We used such methods as: cartographic, GIS technologies, classifications, visual decoding, which allow us to very accurately outline erosion objects on the ground and determine their morphometric characteristics. The assessment of the development of erosion processes in the territory of the Taganrog Bay water protection zone was carried out using a world image from the ArcGIS platform for 2019 with a spatial resolution of up to 1 meter. On the basis of the obtained morphometric characteristics, coefficients are calculated that allow determining the degree of fragmentation of the territory: the coefficient of fragmentation, the average distance between neighboring talvegs of the erosion network, the coefficient of overexposure. It was found that in the chapels of the WPZ of the Taganrog Bay, the indicator of erosive dissection varies from 0 to $3.07 \mathrm{~km} / \mathrm{km}^{2}$, with an average value of $1.53 \mathrm{~km} / \mathrm{km}^{2}$, the thickening of talvegs varies from $0.09 \mathrm{~km}$ to $0.72 \mathrm{~km}$, the indicator of overexposure reaches 0 to $8.12 \%$ in different areas.
\end{abstract}

Keywords: water protection zone, ravine-beam network, horizontal erosion dismemberment, morphometric characteristics of the ravine, geoinformation systems, talweg, Taganrog Bay

Водоохранная зона Таганрогского залива шириной 500 м находится под воздействием ряда негативных природных и антропогенных факторов. Здесь получили развитие такие опасные экзогенные геологические процессы, как абразия берегов, оползнеобразование, овражно-балочная эрозия. Согласно положениям Водного кодекса Российской Федерации эти процессы являются предметом обязательного мониторинга водоохранных зон (ВО3). Положение осложняется еще и тем, что прибрежная зона залива имеет высокую плотность населения и активно используется в хозяйственном отношении, несмотря на установленный специальный водоохранный режим, что приводит к активизации всех вышеперечисленных процессов.

В связи с этим целями исследования являлись оценка густоты эрозионной сети водоохранных зоны Таганрогского залива и ранжирование территории по степени эрозионной расчлененности с применением методов классификации и ГИС. 
Объектом исследования является ВО3 Таганрогского залива, в пределах которой преимущественное развитие получили овраги берегового типа небольшой протяженности.

\section{Материалы и методы исследования}

Овражно-балочная сеть исследовалась с применением инструментария программы ArcMap10.5 на основе мирового снимка из платформы ArcGIS за 2019 г. с пространственным разрешением до 1 м. На первом этапе проводилось дешифрирование эрозионных форм рельефа исследуемой территории по космоснимкам, затем в пределах эрозионных форм выполнялась оцифровка тальвегов для создания слоя ГИС-проекта «Эрозия ВО3 Таганрогского залива». На следующем этапе создавался слой площади и проводился расчет густоты эрозионной сети в ГИС ArcMap10.5 [1].

Объекты, изученные и оцифрованные в ходе визуальной расшифровки, сначала идентифицировались по прямым признакам, которые непосредственно отражаются в изображениях поверхности из космоса. Они включают в себя цвет, тон, размер, форму. В дополнение к прямым важны также косвенные признаки визуальной расшифровки овражной сети. Надежными косвенными признаками или индикаторами эрозионных процессов почвенного покрова являются морфометрические свойства рельефа: предпочтительные формы рельефа, полная фрагментация местности, крутизна склонов, отсутствие растительности.

Для определения длин тальвегов в ArcMap10.5. проводилась их оцифровка в каждой эрозионной форме. Всего было нанесено 497 тальвегов, протяженность которых рассчитывалась по атрибутивным данным полученного слоя. Общая протяженность тальвегов составила 70,2 км.

Нанесение площадей для расчетов эрозионной расчлененности проводилось для полигона, полностью повторяющего границы ВО3 Таганрогского залива. Это официально принятая береговая линия залива и внешняя граница ВО3 шириной 500 м, установленная в Неклиновском, Азовском районах Ростовской области и Щербиновском, Ейском районах Краснодарского края.

Для ранжирования водоохранной зоны Таганрогского залива по степени эрозионной расчлененности осуществлялось деление ее территории на небольшие участки (ячейки), протяженность которых соизмерима с шириной наиболее крупных линей- ных эрозионных форм, встречающихся на исследуемой территории. Площадь элементарной ячейки для расчетов составляла 0,5 км$^{2}$, т.е. исследовался каждый погонный километр водоохранной зоны.

Оценка горизонтальной эрозионной расчлененности проводилась по ряду показателей, включая коэффициент расчлененности территории (I), густоту тальвегов (a) и плотность оврагов (заовраженность) (P).

Коэффициент расчлененности территории определяется по формуле:

$$
\mathrm{I}=\mathrm{L} / \mathrm{S},
$$

где I - коэффициент расчлененности территории, км/км ${ }^{2}, \mathrm{~L}$ - длина тальвегов эрозионной сети, км; $\mathrm{S}$ - площадь, на которой измеряется длина эрозионной сети, км² $[2,3]$.

\section{Результаты исследования и их обсуждение}

В приделах Таганрогского залива показатель I варьирует от 0 км/км² до 3,07 км/км², среднее значение коэффициента равно 1,53 км/км². Низкая степень эрозионной расчлененности наблюдается в дельте Дона от х. Морской Чулек до с. Кагальник и в южной части Таганрогского залива от г. Ейск до ст. Должанская (рис. 1, 2).

Максимальные показатели расчлененности $(3,07$ км/км²) приходятся на Северный берег Таганрогского залива. Так, от х. Морской Чулек до х. Мержаново расчлененность ВОЗ достигает в среднем 1,53 км/ км$^{2}$ с максимумом 3,07 км/км². Западнее, от г. Таганрога до косы Беглицкая, расчлененность территории уменьшается в среднем до 0,98 км/км², достигая максимальных значений у с. Беглица $-2,10$ км/км². На участке Северного брега Таганрогского от с. Беглица до с. Весело Вознесеновка значение коэффициента не превышает $1 \mathrm{\kappa м} / \mathrm{KM}^{2}$.

На Южном берегу Таганрогского залива, к западу от п. Кагальник до п. Стефонидинодар, расчлененность ВОЗ варьирует в широких пределах - от 0,7 км/км ${ }^{2}$ до 2,94 км/км ${ }^{2}$ и в среднем составляет 1,53 км/км². Западнее, до косы Глафировская, этот показатель существенно снижается до 0,24 км/км ${ }^{2}$, и только на небольших участках у сел Семибалки и Порт-Катон увеличивается до 1-2 км/км². Высокой степенью эрозионной расчлененности характеризуется ВО3 Ейского лимана. Среднее значение этого показателя составляет здесь 0,73 км/км² и достигает максимума 3 км/км² в районе с. Ейское Укрепление. 


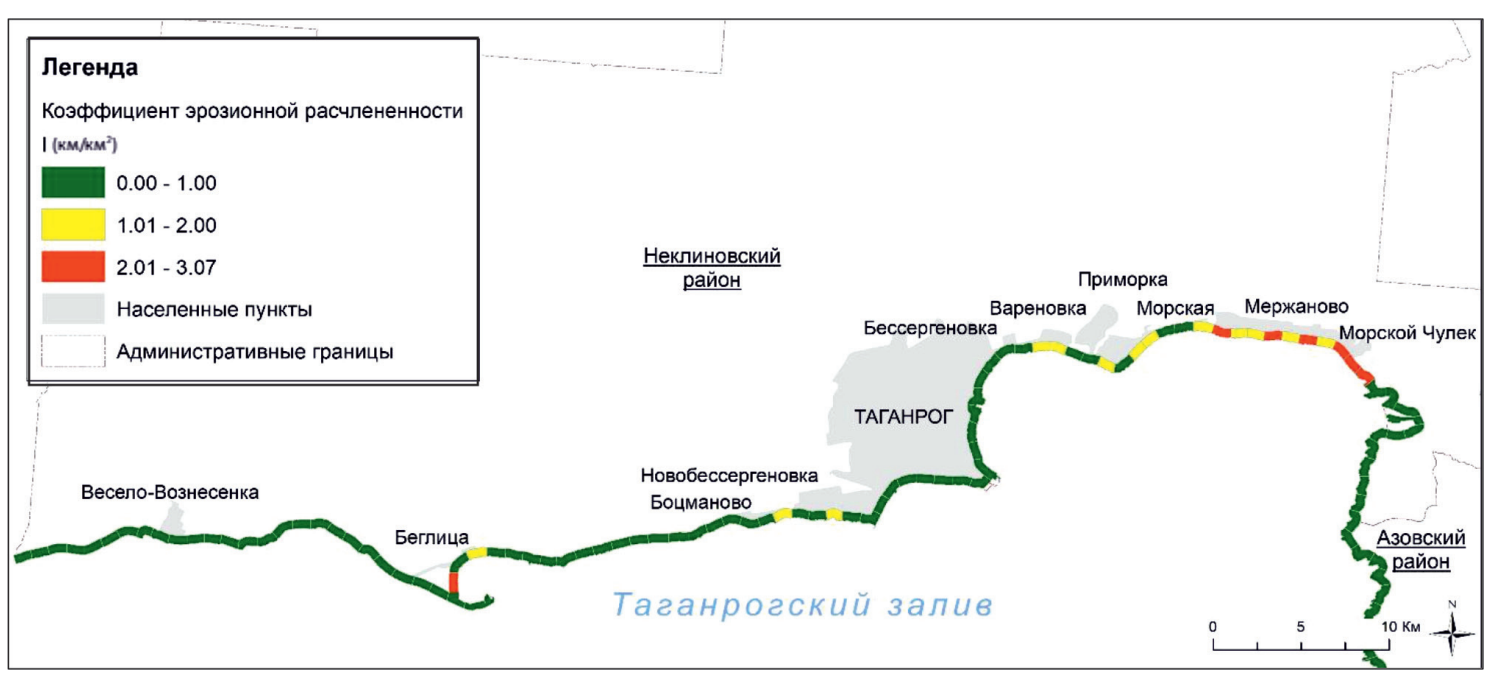

Рис. 1. Карта-схема коэффициента эрозионной расчлененности (I) ВОЗ Северного берега Таганрогского залива

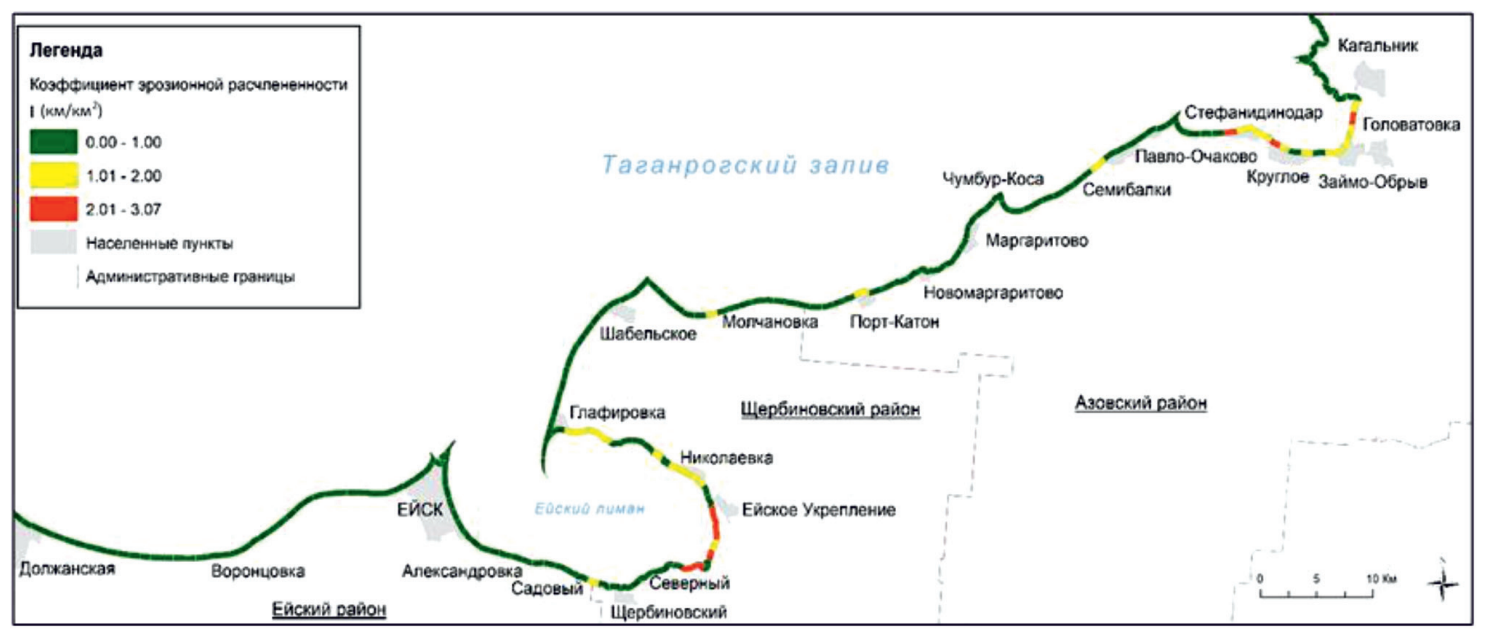

Рис. 2. Карта-схема коэффициента эрозионной расчлененности (I) ВОЗ Южного берега Таганрогского залива

Расчет показателя густоты тальвегов (a) (или среднего расстояния между соседними тальвегами (рис. 3)) выполнен по формуле:

$$
\mathrm{a}=\mathrm{S} / \mathrm{L} \text {, }
$$

где a - среднее расстояние между соседними тальвегами в пределах площади S, L суммарная длина тальвегов на исследуемой площади.

Расчет данного параметра производился аналогично показателю I, при помощи инструментария программного обеспечения ArcGIS. Для Таганрогского залива значение густоты эрозионной сети в среднем составляет 0,06 км. На Северном берегу Таганрог- ского залива самая густая эрозионная сеть зафиксирована на участке ВО3 от х. Морской Чулек до с. Бесергеновка. Здесь расстояние между тальвегами сокращается до 0,14 км. На Южном берегу от с. Кагальник до косы Павло-Очаковской расстояние между тальвегами достигает минимальных значений - 0,03 км для всей исследуемой территории ВОЗ. Локально, к югу от с. Семибалки до с. Глафировка сгущение тальвегов достигает 0,12 км. В водоохранной зоне Ейского лимана этот показатель также высокий - от п. Глафировка до г. Ейск среднее расстояние между соседними тальвегами колеблется от 0,09 км до 0,37 км. 


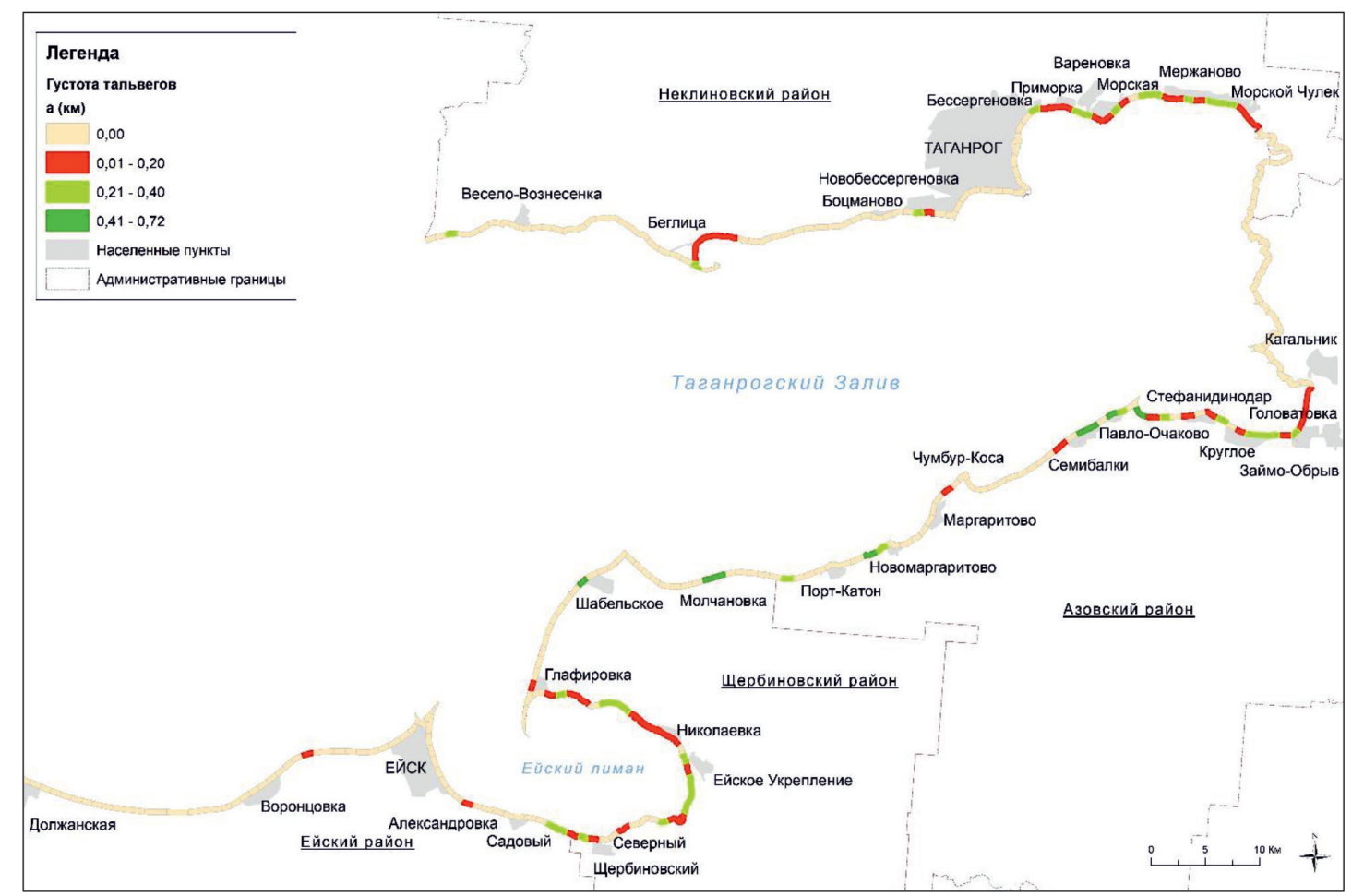

Рис. 3. Карта-схема среднего расстояния между соседними тальвегами (а) в ВОЗ Таганрогского залива



Рис. 4. Пример оценки плотности оврагов на единицу площзади ВОЗ в программном обеспечении ArcGIS

Плотность оврагов в водоохранной зоне $(\mathbf{P})$ определялась как отношение площади оврагов $\mathbf{S}\left(\mathrm{\kappa м}^{2}\right)$ к площади участка

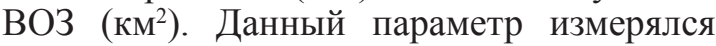
в процентах (\%). На рис. 4 показан пример расчета показателя Р в пределах элементарной ячейки $(0,5$ км X 1,0 км). В ее пределах на ортофотоплане оцифрован овраг, определена его площадь (рис. 4).

В ходе оценки пораженности ВОЗ Таганрогского залива оврагами использовалась следующая классификация $[4,5]$ :

- 0-1 (\%) - практически безовражная;

- 1,01-4,00 (\%) - слабо заовраженная; 
- 4,01-8,00 (\%) - заовраженная;

- 8,01 иболее(\%)-сильнозаовраженная.

В пределах Таганрогского залива показатель $\mathbf{P}$ варьируется от $0 \%$ до 8,12\%. Средняя плотность оврагов в водоохранной зоне Таганрогского залива составляет $2 \%$, т.е. территория относится к слабо заовраженной.

К слабо заовраженным относится ВО3 в районе х. Мержаново (3,74\%), на участках от с. Круглое - с. Семибалки $(2,9 \%)$, с. Новомаргаритовка - с. Глафировка $(1,05-$ $3,03 \%$ ). Большей плотностью оврагов (заовраженные) характеризуются участки ВО3 х. Мержаново - х. Морской Чулек, с. Семибалки, с. Шабельское, плотность оврагов здесь составляет 4-5\%. К сильно заовраженной (это самый высокий показатель) относится территория ВОЗ в районе с. Стефанидинодар - 8,12\%. Большая же часть территории водоохранной зоны Таганрог- ского залива относится к практически безовражной (таблица).

В результате полученных картографических материалов можно выделить участки ВО3 Таганрогского залива, наиболее пораженные эрозионными процессами, где коэффициент расчлененности превышает 3 км/км². В пределах северного берега это район хутора Мержаново, южного участок BO3 от п. Кагальник до п. Стефанидинодар. Сильными эрозионными процессами поражена и большая часть берегов Ейского лимана. На этих участках зафиксировано максимальное для исследуемой территории развитие овражно-балочной сети: коэффициент расчлененности территории I более 3 км/ км $^{2}$, а густота тальвегов достигает 0,17 км, плотность оврагов составляет более 4-8\%, что позволяет отнести эти территории ВО3 Таганрогского залива к заовраженным.

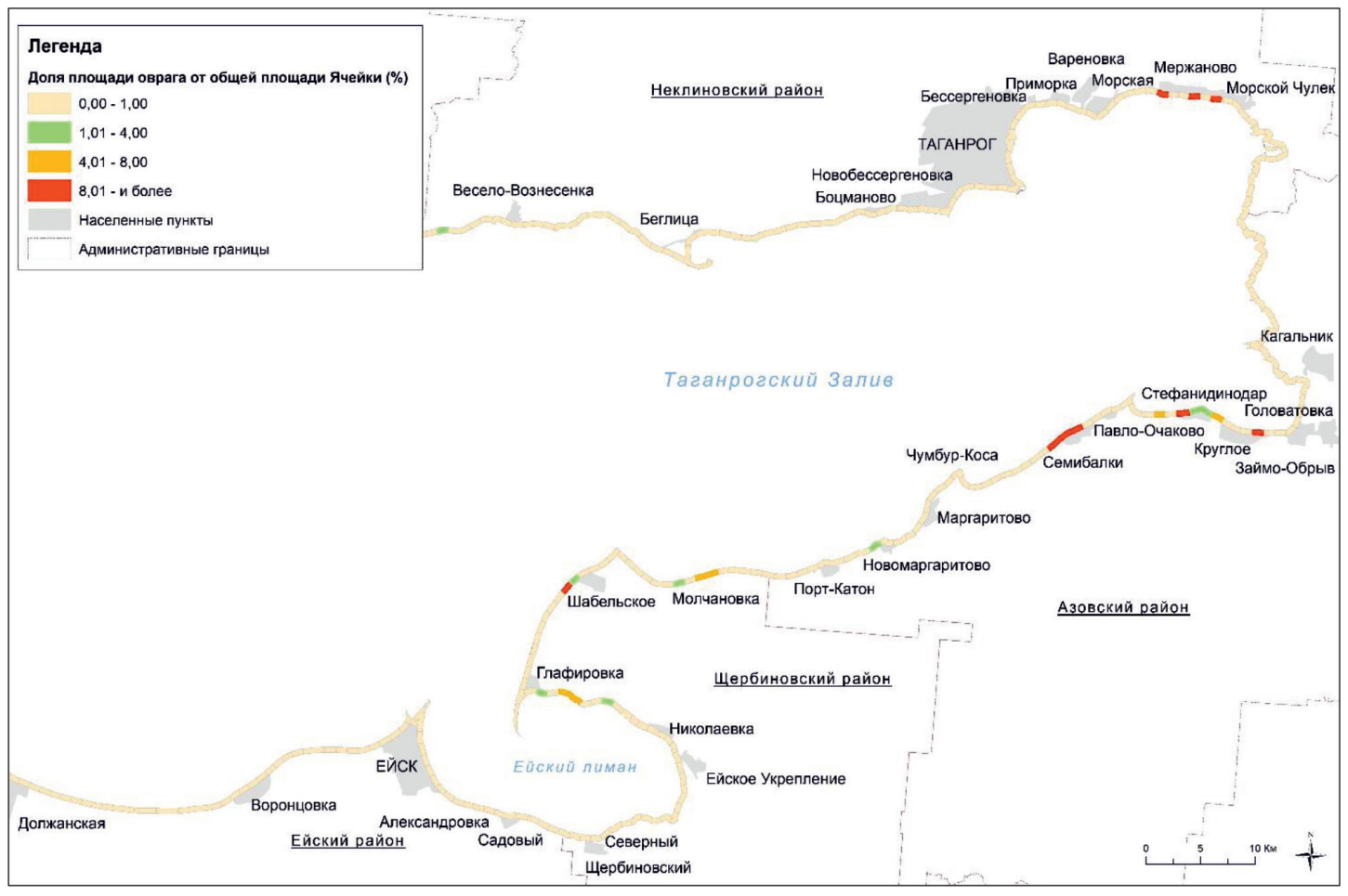

Рис. 5. Карта-схема заовраженности ВОЗ Таганрогского залива (Р)

Ранжирование ВОЗ Таганрогского залива по показателям эрозионной расчлененности

\begin{tabular}{|c|c|c|c|c|c|c|c|c|c|}
\hline $\begin{array}{c}\text { Степень эрозионной } \\
\text { расчлененности }\end{array}$ & \multicolumn{2}{|c|}{$\begin{array}{l}\text { Протяженность ВОЗ } \\
\text { по коэффициенту эрозион- } \\
\text { ной расчлененности (I) }\end{array}$} & \multicolumn{2}{|c|}{$\begin{array}{l}\text { Протяженность ВОЗ } \\
\text { по густоте тальвегов (a) }\end{array}$} & \multicolumn{3}{|c|}{$\begin{array}{l}\text { Протяженность ВОЗ } \\
\text { по плотности оврагов (P) }\end{array}$} \\
\hline & $\begin{array}{c}\text { Градация, } \\
\text { км/км }\end{array}$ & км & $\%$ & Градация, км & км & $\%$ & $\begin{array}{c}\text { Градация, } \\
\%\end{array}$ & км $^{2}$ & $\%$ \\
\hline Высокая & $3,07-2,01$ & 28,15 & 21 & $0,72-0,41$ & 4,5 & 22 & Более 8 & 0,05 & 15 \\
\hline Средняя & $2,0-1,01$ & 48,72 & 37 & $0,40-0,21$ & 5,7 & 28 & $8-4,1$ & 0,11 & 33 \\
\hline Низкая & Менее 1,0 & 36,58 & 42 & Менее 0,2 & 7,3 & 50 & Менее 4 & 0,16 & 52 \\
\hline
\end{tabular}


Таким образом, проведенные с использованием спутниковых снимков и инструментария программы ArcGIS исследования эрозионной сети ВОЗ Таганрогского залива позволили провести ранжирование территории водоохранной зоны Таганрогского залива и выделить наиболее опасные участки, которые необходимо учитывать при разработке противоэрозионных мероприятий и хозяйственной деятельности на этих территориях.

\section{Список литературы / References}

1. Мисиров С.А., Сапрыгин В.В. Беспалова Л.А. Исследование геоморфологических особенностей берегов Таганрогского залива с применением беспилотных летательных аппаратов и ГИС-технологий // Экология. Экономика. Информатика / Серия: Геоинформационные технологии и космический мониторинг. 2018. № 3. С. 42-48.

Misirov S.A., Saprykin V.V. Bespalova L.A. The study of geomorphological features of the shores of the Taganrog Bay using unmanned aerial vehicles and GIS technologies // Ekologiya. Ekonomika. Informatika / Seriya: Geoinformatsionnyye tekhnologii i kosmicheskiy monitoring. 2018. № 3. P. 42 48 (in Russian).

2. Беспалова Л.А., Магаева А.А., Мисиров С.А. Исследование овражно-балочной сети Южного берега Таганрогского залива с использованием беспилотных летательных аппаратов// Известия высших учебных заведений.
Северо-Кавказский регион, Естественные науки. 2019. № 4. C. $77-83$.

Bespalova L.A., Magaeva A.A., Misirov S.A. Investigation of the ravine-beam network of the Southern coast of the Taganrog Bay using unmanned aerial vehicles // Izvestiya vysshikh uchebnykh zavedeniy. Severo-Kavkazskiy region, Yestestvennyye nauki. 2019. № 4. P. 77-83 (in Russian).

3. Скрипка Г.И., Ивлиева О.В., Беспалова Л.А., Филатов А.А., Сапрыгин В.В. Мониторинг опасных береговых процессов Цимлянского водохранилища с использованием ГИС-технологий // ИнтерКарто. ИнтерГИС. Геоинформационное обеспечение устойчивого развития территорий: материалы Междунар. конф. М.: Издательство Московского университета. 2020. Т. 26. № 2. С. 253-263.

Skripka G.I., Ivlieva O.V., Bespalova L.A., Filatov A.A., Saprykin V.V. Monitoring of dangerous coastal processes of the Tsimlyansk reservoir using GIS technologies // InterKarto. InterGIS. Geoinformatsionnoye obespecheniye ustoychivogo razvitiya territoriy: materialy Mezhdunar. konf. M. Izdatel'stvo Moskovskogo universiteta. 2020. Vol. 26. № 2. P. 253-263 (in Russian).

4. Миронова Е.А. Овражность территории СССР // Геоморфология. 1971. № 3. С. 25-35.

Mironova E.A. Ravine of the territory of the USSR // Geomorfologiya. 1971. No. 3. Р. 25-35 (in Russian).

5. Дадахожаев А., Мамаджонов М.М., Хайдаров Ш.Э. Оценка пораженности территории овражной эрозией и интенсивности роста оврагов Наманганских Адыров // Science time. 2018. № 4 (52). С. 95-99.

Dadahozhaev A., Mamadzhonov M.M., Khaydarov Sh.E. Assessment of the area affected by gully erosion and the growth rate of ravines in the Namangan Adyrs // Science time. 2018. № 4 (52). P. 95-99 (in Russian). 